\title{
Novel Use of Ali Shahab Score as a Diagnostic Tool and Decision of Surgical Management in Scalenus Syndrome: A Case Series
}

\author{
Ali Shahab ${ }^{1} \mathbb{D}$, Tjokorda G. B. Mahadewa ${ }^{2} \mathbb{D}$, Wismaji Sadewo ${ }^{3}$, Putu Eka Mardhika ${ }^{2}$, Steven Awyono ${ }^{2}$, \\ Made Bhuwana Putra ${ }^{2}$, Maria Monica ${ }^{2}$ D \\ ${ }^{1}$ Department of Neurosurgery, Gatot Soebroto Army Hospital and Siloam Asri Hospital, Jakarta Indonesia; ${ }^{2}$ Department of \\ Surgery, Neurosurgery Division, Faculty of Medicine, Udayana University, Sanglah Hospital, Bali, Indonesia; ${ }^{3}$ Department of \\ Neurosurgery, Faculty of Medicine, Indonesia University, Dr Cipto Mangunkusumo Hospital, Jakarta, Indonesia
}

Edited by: Igor Spirosk Citation: Shahab A, Mahadewa TGB, Sadewo W, ardhika PE, Awyono S, Putra MB, Mtica M. Novel Use of Surgical Management in Scalenus Syndrome: A Case Series. Open-Access Maced J Med Sci. 2022 Feb 28 Series. Open-Access Maced J Med Sci. 2022 Feb 28
10(B):432-437. https://doi.org/10.3889/oamjms.2022.8510 Keywords: Scalenectomy; Scalenus syndrome; Scalenus triangle; Sympathetic hypertonia, Case series Corresponding author: Tjokorda G. B. Mahadewa Neurosurgery Division, Department of Surgery, Faculty
of Medicine, Udayana University, Sanglah Hospital, Bali, E-mail: tjokmahadewa@unud.ac.id Received: 04-Jan-2022
Revised: $17-F e b-2022$ Accepted: 19-Feb-2022 Copyright: $\odot 2022$ Ali Shahab, Tjokorda G. Mahadewa, Wismaji Sadewo, Putu Eka Mardhika, Steven Awyono, Made Bhuwana Putra, Maria Monica Funding: This research did not receive any financial Competing Interest: The authors have declared that no competing interest exist Open Access: This is an open-access article distribute under theil 4.0 or

\begin{abstract}
BACKGROUND: Scalenus syndrome is a collection of symptoms as the consequences of nerve and vascular compression within the scalene triangle. However, the entity has long been forgotten in publications and is difficult to recognize. The diagnosis of scalenus syndrome is mainly based on clinical findings. The Ali Shahab score is a new scoring system, generated based on clinical symptoms of scalenus syndrome.

AIM: In this study, we presented a case series of scalenus syndrome patients who were diagnosed and decide to be managed surgically based on Ali Shahab score. We also reported post-operative outcomes following scalenectomy in our series.

METHODS: This was a case series including patients with scalenus syndrome in Gatot Soebroto Army Hospital Indonesia, and Siloam Asri Hospital, Indonesia, between 2016 and 2021. The diagnosis of scalenus syndrome was made based on Ali Shahab score with a value of more than 7. All patients were performed scalenectomy to decompress the stenotic subclavian artery and brachial plexus from surrounding fibrotic tissue. Eligible subjects were assessed for sex, side of symptoms, pre-operative and post-operative Ali Shahab score, and post-operative outcome.

RESULTS: We included 96 patients with scalenus syndrome in this case series. Most of the included patients were male $(59.4 \%)$ and experienced scalenus syndrome on the right side $(76 \%)$. The average pre-operative $\mathrm{Al}$ Shahab score in our series was $7.12 \pm 0.48$ and the post-operative score was $0.11 \pm 0$. Regarding post-operative outcomes, more than half of the patients experienced symptoms reduction with $38.5 \%$ of patients experiencing complete resolution of symptoms following scalenectomy.

CONCLUSION: The application of the Ali Shahab score may be used as a diagnostic tool and decision of surgical management for scalenus syndrome patients. Decompression of the subclavian artery and releasing brachial plexus
\end{abstract} from surrounding fibrotic tissue can improve clinical symptoms in scalenus syndrome patients.

\section{Introduction}

Scalenus syndrome is a collection of symptoms resulting from brachial plexus and subclavian artery compression within the scalene triangle. The symptoms include pain, numbness, motoric, and sensory disturbances [1], [2], [3]. The compression of neurovascular structure within the scalene triangle is caused by secondary hypertrophy of the anterior scalene muscle due to muscle spasm [4]. Compression of these structures leads to vascular changes and brachial plexus neuritis [5]. The term "scalenus syndrome" had been completely forgotten since the late 1950s, as the term thoracic outlet syndrome (TOS) began to rise. Scalenus syndrome was considered similar to TOS [6]. However, we suggested that these two clinical entities are different. TOS is a collection of symptoms caused by the compression not only in the scalene triangle but also the costoclavicular space and retropectoralis minor space [7], [8]. Moreover, TOS is caused by static pathologies; meanwhile, scalenus syndrome is caused by dynamic pathology, which is the hardening of the anterior scalene muscle [1], [6], [8], [9]. The hardening of the anterior scalene muscle can occur due to fibrosis, trauma, and lifestyle that require repetitive shoulder movement [9], [10].

Diagnosing scalenus syndrome remains a challenge as there are no objective measures or criteria for diagnosis [8], [9], [11], [12]. The diagnosis of scalenus syndrome is mainly based on clinical findings due to the subclavian artery and brachial plexus compression. Work-up examinations such have limitations to diagnose scalenus syndrome [7], [8], [12]. We proposed Ali Shahab score as a mean to overcome the challenges in diagnosing scalenus syndrome as the score was generated based on clinical findings. Because the term TOS had overridden scalenus syndrome completely, there are no recent studies discussing scalenus syndrome, and no prior scoring system could be referenced. In this study, we presented a case series of scalenus syndrome patients diagnosed 
and managed surgically based on Ali Shahab score. We also reported post-operative outcomes following scalenectomy in our series.

\section{Methods}

\section{Research design and study subjects}

This study was a retrospective case series involving a multicenter that observes patients with scalenus syndrome in Gatot Soebroto Army Hospital, Indonesia, and Siloam Asri Hospital, Indonesia, between 2016 and 2021. Consecutive sampling was chosen and 96 patients were included in the study. The study was approved by the Ethical Committee of Gatot Soebroto Army Hospital, Indonesia, and Siloam Asri Hospital. The research was done with strict adherence to the tenets of the Declaration of Helsinki. All patients within the study were explained thoroughly about the study and had signed informed consent regarding it.

Our inclusion criteria were: All patients diagnosed with scalenus syndrome in the time frame. The diagnosis of scalenus syndrome was made based on Ali Shahab score with a value of 7 or higher. The detail of the Ali Shahab score is shown in Table 1. This is a new scoring system, and thus, we have no prior reference to the score. Patients with tinnitus were excluded because a neurogenic problem or conductive abnormality could cause this symptom. Personal information of the patients (name and birth date) was omitted from the data and replaced with a new random subject identifier in an effort of protecting patient confidentiality.

Table 1: The Ali Shahab score and its interpretation

\begin{tabular}{lll}
\hline Component & Interpretation & Score \\
\hline Extremity rigidity & $\begin{array}{l}\text { The presence of ipsilateral upper and/or lower } \\
\text { extremity rigidity indicates a positive result. } \\
\text { The presence of neurological signs such as pain } \\
\text { or paresthesia on the upper extremity during } \\
\text { maneuver indicates a positive result. } \\
\text { Difficulty in elevating ipsilateral leg during } \\
\text { maneuver indicates a positive result }\end{array}$ & 2 \\
$\begin{array}{l}\text { Difficulty in elevating } \\
\text { leg }\end{array}$ & 2 \\
Cervical tenderness & $\begin{array}{l}\text { Thesence of cervical tenderness indicates a } \\
\text { positive result. }\end{array}$ & 1 \\
Loss of pulse & $\begin{array}{l}\text { Reduction or loss of pulse during maneuver } \\
\text { indicate positive results }\end{array}$ & 1 \\
Cyanotic fingers & $\begin{array}{l}\text { The presence of cyanotic fingers during } \\
\text { maneuver indicate positive results }\end{array}$ & 1 \\
\hline $\begin{array}{l}\text { Total score interpretation: }<5 \text { is unlikely scalenus syndrome; 5-6 is indeterminate, probably caused by } \\
\text { other pathologies; } 7-9 \text { is scalenus syndrome, requiring surgical management to decompress subclavian } \\
\text { artery and brachial plexus. }{ }^{*} \text { Examination procedures include extension and abduction of the ipsilateral arm } \\
\text { while turning the head to the contralateral side. }\end{array}$
\end{tabular}

Eligible subjects were assessed for sex, side of symptoms, pre-operative and post-operative Ali Shahab score, and post-operative outcome. Ali Shahab score was generated based on six variables: Extremity rigidity, neurological finding, difficulty in elevating the leg, cervical tenderness, loss of pulse, and cyanotic finger. Extremity rigidity, neurological finding, and inability to elevate the leg were given 2 points, while cervical tenderness, loss of pulse, and cyanotic finger were given 1 point. The detail of the Ali Shahab score is shown in Table 1.

Post-operative score and outcome were measured in the 1-month hospital follow-up after surgery, 31 patients (32.3\%) were loss of follow-up. We divided post-operative outcomes into four groups, which were A, B, C, and D. Group A was defined as complete resolution of symptoms; Group B was described as an incomplete resolution of symptoms; Group C was defined as persistent symptoms, and Group D was defined as loss of follow-up.

\section{Scalenectomy technique}

Patients with an Ali Shahab score of 7 or higher were performed scalenectomy. Under the general anesthesia, the patient was placed in a supine position with the head positioned in neck extension, tilting to the contralateral side of the operation. Previous supraclavicular scalenectomy techniques had been described before and used in this study [7], [10], [13]. A transverse incision was done above the medial third of the clavicle and deepened layer by layer. The external jugular vein and subclavian vein were retracted. Scalenectomy was done to decompress neurovascular structure within the scalene triangle. The ipsilateral subclavian artery was exposed, and the stenotic lumen was identified due to fibrotic tissue compressing the surrounding artery. After identification of stenotic lumen, the decompression was performed to release compression of the subclavian artery by surrounding fibrotic tissue. Decompression was performed until the vessel lumen on the stenotic area was similar to the normal lumen of the subclavian artery. Brachial plexus was also exposed and released from surrounding fibrotic tissue.

\section{Statistical analysis}

All data were analyzed descriptively with Statistical Package for the Social Sciences (SPSS 26) software. Variable sex, side of symptoms, and postoperative outcome were presented as categorical variables. Mean and standard deviation of preoperative and post-operative Ali Shahab scores were also calculated. This case series has been reported in line with the PROCESS Guideline [14].

\section{Results}

\section{Case illustration}

Male, 53 years old, complained of pain on the head, neck, shoulder, upper arm, chest, abdomen, lower back, thigh, and leg in the past 4 years before. 


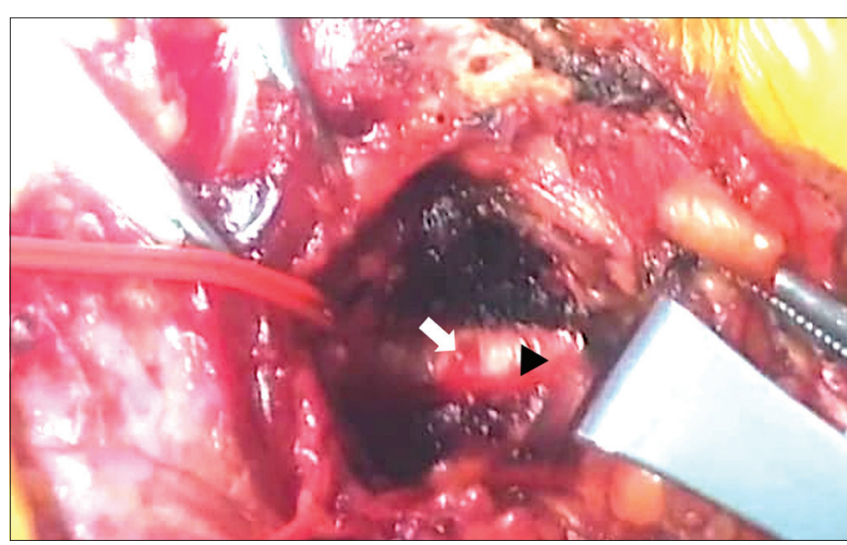

Figure 1: Intraoperative view of scalenectomy for scalenus syndrome before decompression was performed. In this intraoperative view, we can see normal lumen of subclavian artery (white arrow) and narrow lumen subclavian artery (black arrowhead) due to compression of fibrotic tissue surrounding the vessel

All of the symptoms were experienced by the patient on the right side. The patient also complained of fatigue, shortness of breath, and difficulty walking. The patient was diagnosed with scalenus syndrome with an Ali Shahab score of 7 . The patient was managed surgically with scalenectomy based on Ali Shahab score. During surgery, the right subclavian artery was identified and revealed stenosis of the subclavian artery due to compression of surrounding fibrotic tissue (Figure 1). Decompression of the subclavian artery was performed until the vessel lumen was similar in size to the normal vessel lumen (Figure 2a). The brachial plexus was also exposed and released from surrounding fibrotic tissue (Figure 2b). Following the surgery, all of the symptoms were improved entirely, and the patient can also walk normally.

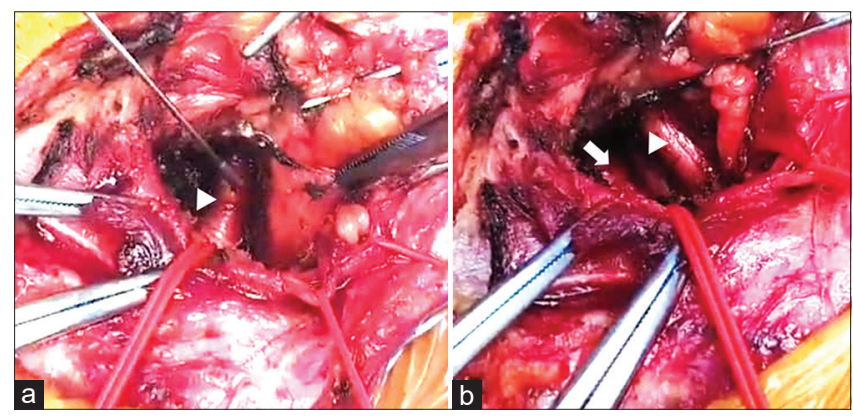

Figure 2: Intraoperative view of scalenectomy for scalenus syndrome after decompression was performed. A. The lumen of the subclavian artery had been decompressed, and a similar size of the vascular lumen (white arrowhead) can be seen; $B$. In this intraoperative view, decompressed subclavian artery (white arrow) can be seen, and decompression of brachial plexus was also performed (white arrowhead)

\section{Case series}

We included 96 patients with scalenus syndrome in this case series. As shown in Table 2, most of the included patients were male (59.4\%) and experienced scalenus syndrome on the right side (76\%). The average pre-operative Ali Shahab score was
Table 2: Descriptive characteristic of samples

\begin{tabular}{lll}
\hline Variable & $\mathrm{n}(\%)$ & Mean \pm SD \\
\hline Sex & $57(59.4)$ & \\
$\quad$ Male & $39(40.6)$ & \\
Female & $20(20.8)$ & \\
Side & $76(79.2)$ & \\
$\quad$ Left & & \\
Right & $37(38.5)$ & \\
Post-operative outcome & $15(15.7)$ & $7.12 \pm 0.48$ \\
A & $13(13.5)$ & $0.11 \pm 0$ \\
B & $31(32.3)$ & \\
C & & \\
D & & \\
Ali Shahab score & & \\
Pre-operative & & \\
Post-operative & & \\
\hline
\end{tabular}

$7.12 \pm 0.48$, and the post-operative score was $0.11 \pm 0$. Regarding post-operative outcomes, more than half of the patients experienced symptoms reduction, with $38.5 \%$ of patients experiencing complete resolution of symptoms following scalenectomy. This result could be higher since we could not determine the post-operative outcome in $32.3 \%$ of patients due to loss of follow-up. The total follow-up duration was 1 month. No patient died during the study and no intraoperative or postoperative complications.

\section{Discussion}

There are three anatomic spaces in the thoracic inlet: Scalene triangle, costoclavicular space, and retropectoralis minor space [1], [15], [16], [17], [18]. The compression of the neurovascular structures in the scalene triangle produces clinical symptoms of scalenus syndrome [3], [19]. The scalene triangle is the most medial compartment of the thoracic inlet and bordered anteriorly by anterior scalene muscle, posteriorly by middle scalene muscle, and inferiorly by the first rib. The neurovascular structures in the scalene triangle are the upper, middle, and lower trunk of the brachial plexus and subclavian artery [1], [15], [17], [18].

The diagnosis of scalenus syndrome is mainly based on clinical findings due to compression of the subclavian artery and brachial plexus [8], [9], [11], [12]. Computed tomography imaging is valuable in assessing bony abnormality but challenging to visualize soft tissue, fibromuscular band, and neural structure in the scalene triangle [8], [20]. Ultrasonography is also limited in visualizing neuromuscular components and is highly dependent on the operator [21]. Magnetic resonance imaging is superior in visualizing neurovascular and muscle tissue. However, this modality is limited in visualizing fibrotic muscle [22], [23]. Therefore, due to the limitation of the above examination, clinical findings remain the primary diagnostic tool in scalenus syndrome.

The Ali Shahab score was a new scoring system - generated based on clinical findings of scalenus syndrome due to brachial plexus and 
subclavian artery compression. The compression of the brachial plexus and subclavian artery probably also causes a sympathetic hypertonic state, contributing to the clinical manifestation of scalenus syndrome. The extension and abduction of the arm are causing worsening of symptoms [24]. It occurs because the scalene triangle is narrow at-rest state and becomes narrower on specific movements like downward traction of the arm [25], [26].

In our case series, the extremity rigidity was found in scalenus syndrome patients and improved following subclavian artery and brachial plexus decompression. The extremity rigidity is probably caused by sympathetic hypertonic. Sympathetic impulse had a direct effect on the intrafusal muscle fiber. Sympathetic impulses cause contraction of intrafusal muscle fiber and lead to the hypertonic reflex of the muscle [27]. We theorized that the hypertonic reflex of the muscle leads to rigidity of extremity, which causes difficulty in elevating the leg.

The neurologic finding in scalenus syndrome is caused by compression of neural structure in the scalene triangle. It can be caused by compression of the upper or lower plexus. The compression of the upper plexus manifests in the supraclavicular region, while lower plexus compression manifests in the ulnar forearm, axillary, and anterior shoulder [24]. The neurological manifestations include pain on the upper extremity, atrophy of intrinsic muscle of the hand, paresthesia, and muscle twitch [3], [10], [18].

Cervical tenderness is common in the scalenus syndrome [3], [24]. The compression of the scalene muscle, which is located above the clavicle, produces radiating pain in ulnar nerve distribution [3]. The sympathetic hypertonic state may cause loss of pulse and cyanotic finger due to compression of the subclavian artery and lower brachial plexus. The subclavian artery is surrounded by sympathetic nerve rami [19]. The subclavian artery stenosis and compression probably cause transmission of an impulse to several sympathetic rami and nerves of Kuntz, which lead to vascular changes [25]. The manifestation of sympathetic activation is vasospasm, poor capillary refill, and lower temperature [3], [28].

The sympathetic hypertonic state can also occur due to compression of the lower brachial plexus. The brachial plexus is mainly divided into supra-, retro-, and infra-clavicular plexus. The supraclavicular plexus is further divided into three parts, which are the upper (C5 and C6), middle (C7), and lower (C8 and T1) plexus [16]. There are many distributions of sympathetic rami in the lower brachial plexus. The main sympathetic ganglions for the upper extremity are ganglion middle cervical and stellate. The ganglion stellate is located at the level of the first rib and is formed by sympathetic ganglion cervical and first thoracic [29]. In addition to the loss of pulse and cyanotic finger, the Raynaud phenomenon may occur due to overactive sympathetic activity because of its proximity to the roots of the lower brachial plexus [22].

Loss of pulse and cyanotic finger can also be caused by subclavian artery compression, which exhibits a reduction of pulse, especially when the head is turned contralateral and deep inspiration is taken [3], [24], [28]. It was confirmed by Doppler examination on the distal extremity, which revealed a reduction of blood when the head was turned to the contralateral side [19].

In our case illustration, the patient with scalenus syndrome complained of chest pain that radiated to the upper arm, similar to pectoral angina. The possible explanation of this phenomenon is probably due to sympathetic hypertonic. As we know, the coronary artery is innervated by the sympathetic nervous system, which also influences heartbeat and blood flow in the coronary artery. In continuous sympathetic hypertonic conditions, such as stress (high cortisol release), administration of anti-depressant medication, decongestant, and hypothermia, the coronary artery's vasoconstriction occurs and is followed by a decrease of blood flow, which eventually leads to myocardial ischemia. Myocardial ischemia is manifested as angina or chest pain that radiated to the left arm. It probably occurs because the coronary artery's sympathetic impulse is transmitted through the ganglion stellate to the brachial plexus that innervates the left arm [30], [31]. In scalenus syndrome, the subclavian artery is compressed by anterior scalenus muscle, which leads to narrowing of the vessel lumen. The sympathetic nervous system also innervates the subclavian artery [1], [7], [11]. We hypothesized that the stenotic subclavian artery and compression by the scalenus muscle, the pulse of the subclavian artery, lead to the sympathetic impulse to ganglion stellate. The efferent impulse will be transmitted to the coronary artery and lead to coronary vasoconstriction and angina from the ganglion stellate.

In our case series, most scalenus syndrome patients were male. This does not conform with other studies that stated that women are more frequent to experience scalenus syndrome [18], [32]. Women are more prone to scalenus syndrome due to their posture that allows lower shoulder girdle [3].

The scalenus syndrome more frequently occurred on the right side in our series. This is in accordance with other studies [18], [32]. The shoulder girdle has a key role in scalenus syndrome. It gradually descends following the aging process and pushes the brachial plexus into the scalene triangle. It will cause the brachial plexus to be more prone to compression within the scalene triangle. The right-side shoulder is usually dropping lower in adults [3]. The right side is the most frequent location of scalenus syndrome because in adults, the right-side shoulder is usually dropping lower. 
Based on the intraoperative finding, we found stenosis of the subclavian artery due to compression by surrounding fibrotic tissue. This is supported by another study that reported the result of a small and sclerotic subclavian artery due to compression by anterior scalene muscle [24]. In addition, the anterior scalene muscle was large, very tense, and covered by a thickened fibrous band [3], [24]. There was evidence of inflammation, degeneration, hypertrophy, and fibrosis of anterior scalene muscle based on microscopic findings [2], [3].

More than half of the patients experienced a reduction of symptoms; some even had complete resolution of symptoms following scalenectomy to decompress the subclavian artery and brachial plexus in our case series. The post-operative Ali Shahab score was also improved from an average of 7 preoperatively to 0 postoperatively. In Group B, the incomplete resolution of symptoms mainly was right hypochondriac pain due to cholecystitis, pain on the knee, insufficient improvement of motoric, and paresthesia on the upper arm.

Regarding surgical outcomes in scalenectomy, we could not find any recent updates. Kallio and Rokkane reported the excellent outcome of scalenectomy in scalenus syndrome [33]. Spurling and Bradford also wrote of fast recovery of sensory disturbance and pain relief [3]. Donald and Morton also reported favorable outcomes of scalenectomy [24]. The motoric improvement of the hand was probably caused by vascular decompression [33].

Based on the outcome result, we proposed that the Ali Shahab score can be used to diagnose scalenus syndrome due to compression of the subclavian artery and brachial plexus. After the decompression of the subclavian artery and brachial plexus, the score was reduced to 0 in some of the patients. Due to the limited available resources discussing the phenomenon in recent years and the difficulty in diagnosing the condition, we proposed that the Ali Shahab score be used as the protocol for surgical management of scalenus syndrome. However, we are aware of the limitations our study has. Since this is a retrospective study with consecutive sampling, patient selection and treatment may be biased. Furthermore, the short follow-up period and a small number of samples could have influenced the study. This is still a preliminary study of the scoring system. Further prospective, larger sample, and longer follow-up time studies are needed to validate this novel scoring system.

\section{Conclusion}

This study is a reminder that scalenus syndrome is still a prominent diagnosis. If not recognized early, this entity could severely debilitate patients' quality of life. The application of the Ali Shahab score may be used as a diagnostic tool and decision of surgical management for scalenus syndrome patients. Decompression of the subclavian artery and releasing brachial plexus from surrounding fibrotic tissue can improve clinical symptoms in scalenus syndrome patients. A larger, prospective, and longer follow-up study is needed to determine the true functionality of this score.

\section{Informed Consent}

The study was approved by the Ethical Committee of Gatot Soebroto Army Hospital, Indonesia, and Siloam Asri Hospital. The research was done with strict adherence to the tenets of the Declaration of Helsinki. All patients within the study were explained thoroughly about the study and had signed informed consent regarding it.

\section{Authors' Contributions}

All authors contributed equally in the process of manuscript preparation.

\section{References}

1. Jones MR, Prabhakar A, Viswanath $O$, Urits I, Green JB, Kendrick JB, et al. Thoracic outlet syndrome: A comprehensive review of pathophysiology, diagnosis, and treatment. Pain Ther. 2019;8(1):5-18. https://doi.org/10.1007/s40122-019-0124-2 PMid:31037504

2. Gage M, Parnell H. Scalenus anticus syndrome. Am J Surg. 1947;73(2):252-68. https://doi.org/10.1016/0002-9610(47)90320-6 PMid:20282210

3. Spurling RG, Bradford FK. Scalenus neurocirculatory compression. Ann Surg. 1938;107(5):708-15. https://doi. org/10.1097/00000658-193805000-00008 PMid: 17857175

4. Ochsner A, Gage M, DeBakey M. Scalenus anticus (naffziger) syndrome. Am J Surg. 1935;28:699-77.

5. Swank RL, Fiorindo SA. The scalenus anticus syndrome: Types; their characterization, diagnosis, and treatment. Arch Neurol Psychiatry. 1944;51(5):432-45. https://doi.org/10.1001/ archneurpsyc.1944.02290290019004

6. Gkarsioudis K, Papagrigorakis E, Skandalakis P, Filippou D. Thoracic outlet syndrome: Historical aspects of anatomy and physiology. Int J New Technol Res. 2018;4(3):81-4.

7. Lim C, Kavousi Y, Lum YW, Christo PJ. Evaluation and management of neurogenic thoracic outlet syndrome with an 
overview of surgical approaches: A comprehensive review. J Pain Res. 2021;14:3085-95. https://doi.org/10.2147/JPR.S282578 PMid:34675637

8. Povlsen S, Povlsen B. Diagnosing thoracic outlet syndrome: Current approaches and future directions. Diagnostics (Basel). 2018;8(1):21. https://doi.org/10.3390/diagnostics8010021 PMid:29558408

9. Nava FB, Barrial M, Martínez A, Alonso E, Barrena S, Martínez L, et al. Thoracic outlet syndrome in adolescents: A case series. Cir Pediatr. 2020;33(3):110-4.

PMid:32657093

10. Baltopoulos P, Tsintzos C, Prionas G, Tsironi M. Exercise-induced scalenus syndrome. Am J Sports Med. 2008;36(2):369-74. https://doi.org/10.1177/0363546507312166

PMid:18202297

11. Golden N, Shahab A, Mahadewa TG, Mardhika PE, Awyono S, Putra MB, et al. Scalenus syndrome: A literature review. Open Access Maced J Med Sci. 2021;9:6-12. Available from: https://www.oamjms.eu/index.php/mjms/article/view/5571. [Last accessed on 2022 Jan 20].

12. Dessureault-Dober I, Bronchti G, Bussières A. Diagnostic accuracy of clinical tests for neurogenic and vascular thoracic outlet syndrome: Asystematic review. J Manipulative Physiol Ther. 2018;41(9):789-99. https://doi.org/10.1016/j.jmpt.2018.02.007 PMid:30871714

13. Yin ZG, Gong KT, Zhang JB. Outcomes of surgical management of neurogenic thoracic outlet syndrome: A systematic review and bayesian perspective. J Hand Surg Am. 2019;44(5):416. e1-17. https://doi.org/10.1016/j.jhsa.2018.06.120 PMid:30122304

14. Agha RA, Borrelli MR, Farwana R, Koshy K, Fowler AJ, Orgill DP, et al. The PROCESS 2018 statement: Updating consensus preferred reporting of CasE series in surgery (PROCESS) guidelines. Int J Surg. 2018;60:279-82. https://doi.org/10.1016/j. ijsu.2018.10.031

PMid:30359781

15. Kuhn JE, Lebus GF V, Bible JE. Thoracic outlet syndrome. J Am Acad Orthop Surg. 2015;23(4):222-32. https://doi.org/10.5435/ JAAOS-D-13-00215

PMid:25808686

16. Ferrante $M$, Ferrante $N$. The thoracic outlet syndromes: Part 1. Overview of the thoracic outlet syndromes and review of true neurogenic thoracic outlet syndrome. Muscle Nerve. 2016;55(6):782-93. https://doi.org/10.1002/mus.25536 PMid:28006844

17. Hussain MA, Aljabri B, Al-Omran M. Vascular thoracic outlet syndrome. Semin Thorac Cardiovasc Surg. 2016;28(1):151-7. https://doi.org/10.1053/j.semtcvs.2015.10.008 PMid:27568153

18. Atasoy E. Thoracic outlet syndrome: Anatomy. Hand Clin. 2004;20:7-14. https://doi.org/10.1016/s0749-0712(03)00078-7 PMid: 15005377

19. Winsor T, Winsor D, Mikail A, Sibley AE. Thoracic outlet syndromes-application of microcirculation techniques and clinical review. Angiology. 1989;40(9):773-82. https://doi. org/10.1177/000331978904000901 PMid:2527480

20. Bilbey JH, Müller NL, Connell DG, Luoma AA, Nelems B. Thoracic
outletsyndrome:EvaluationwithCT.Radiology. 1989;171(2):381-4. https://doi.org/10.1148/radiology.171.2.2704801

PMid:2704801

21. Weaver ML, Lum YW. New diagnostic and treatment modalities for neurogenic thoracic outlet syndrome. Diagnostics (Basel). 2017;7(2):28. https://doi.org/10.3390/diagnostics7020028 PMid:28555024

22. Aralasmak A, Cevikol C, Karaali K, Senol U, Sharifov R, Kilicarslan $\mathrm{R}$, et al. MRI findings in thoracic outlet syndrome. Skeletal Radiol. 2012;41(11):1365-74. https://doi.org/10.1007/ s00256-012-1485-3

PMid:22782291

23. Hardy A, Pougès $C$, Wavreille $G$, Behal $H$, Demondion $X$, Lefebvre G. Thoracic outlet syndrome: Diagnostic accuracy of MRI. Orthop Traumatol Surg Res. 2019;105(8):1563-9. https:// doi.org/10.1016/j.otsr.2019.09.020

PMid:31732398

24. Donald JM, Morton BF. The scalenus anticus syndrome with and without cervical RIB. Ann Surg. 1940;111(5):709-23. https:// doi.org/10.1097/00000658-194005000-00004

PMid: 17857578

25. Williams AF. The role of the first RIB in the scalenus anterior syndrome. J Bone Joint Surg Br. 1952;34-B:200-3. https://doi. org/10.1302/0301-620X.34B2.200

PMid:12999894

26. Huang JH, Zager EL. Thoracic outlet syndrome. Neurosurgery. 2004;55:897-902; discussion 902-3. https://doi.org/10.1227/01. neu.0000137333.04342.4d PMid: 15458598

27. Grassi C, Passatore M. Action of the sympathetic system on skeletal muscle. Ital J Neurol Sci. 1988;9(1):23-8. https://doi. org/10.1007/BF02334403 PMid:2965685

28. Tanna J. Scalenotomy: An analysis of eleven cases done for scalenus anticus syndrome. Ann Surg. 1947;125(1):80-8. https://doi.org/10.1097/00000658-194701000-00008 PMid:17858916

29. Kuntz A. Distribution of the sympathetic rami to the brachial plexus: Its relation to sympathectomy affecting the upper extremity. Arch Surg. 1927;15(6):871-7. https://doi.org/10.1001/ archsurg.1927.01130240044003

30. Elias M. Cervical sympathetic and stellate ganglion blocks. Pain Physician. 2000;3(3):294-304.

PMid: 16906187

31. Kikuta S, Dalip D, Loukas M, Iwanaga J, Tubbs R. Jaw pain and myocardial ischemia: A review of potential neuroanatomical pathways. Clin Anat. 2019;32:476-9. https://doi.org/10.1002/ ca. 23367

PMid:30847968

32. Raaf J. Surgery for cervical rib and scalenus anticus syndrome. J Am Med Assoc. 1955;157(3):219-23. https://doi.org/10.1001/ jama.1955.02950200017005

PMid: 13211340

33. KallioE,RokkanenP.Effectofscalenotomyintheso-calledscalenus anticus syndrome. Acta Orthop Scand. 1965;35(1-4):59-66. https://doi.org/10.3109/17453676508989339

PMid:14229499 